\title{
Integrating Lean, Green, and Resilience Criteria in a Sustainable Food Supply Chain Planning Model
}

\author{
Kanchan Das \\ College of Engineering and Technology \\ East Carolina University, Greenville, NC 27858, USA \\ E-mail: dask@ecu.edu
}

(Received October 29, 2108; Accepted November 25, 2018)

\begin{abstract}
Given the current food supply chain (SC) situations that generates substantial amount of wastes and emissions $\left(\mathrm{CO}_{2} \mathrm{e}\right)$ starting from input supply point to the marketing; increasing demand for food for growing population, requirements of water, and energy for processing the food, it is not sustainable. In addition, it is exposed to natural calamity and risks from supply, production and quality system failures and other disruptions and disasters. As such a sustainable food SC network design model is proposed that integrates resilience criteria, lean, and green based practices to overcome limitations of the current practices of the chain and improve its performances. The research designs and plans sustainable food collection regional grids, their potential locations, capacities, operations, establishment of relationship with food processing centers, and big-name retailers. The model is defined as a deterministic model to improve sustainability performance of a grid based supply chain network. Each grid is run by food collection cooperatives formed by the local farmers or small business organization. The research contributes by designing and planning potential grid locations, their capacities and integrates resilience criteria and lean based practices for improving sustainability performances. Applicability of the model is illustrated by the grid network of an example region (state).
\end{abstract}

Keywords- Sustainable food supply chain, Resilience criteria, Lean and green criteria, Regional supply chain grids, Food collection cooperatives.

\section{Introduction}

Food production, processing and supply constitute the fundamental items for one of the most critical supply requirements for the survival and wellbeing of our society. Existing food supply chain (SC) is not sustainable considering its generation of wastes and emissions $\left(\mathrm{CO}_{2} \mathrm{e}\right)$ and increasing demand for food for growing population, requirements of water, and energy for processing the food (Beitzen-Heineke, et al. 2017). The wastes and environmental concerns from food SC is at such an extent that UNEP considers agriculture and food consumption are the two most important drivers of environmental pressures (UNEP, 2010) for habitat change, climate change and water use and toxic emissions. It is an imperative to identify the SC points for such generation of wastes and emissions including their reasons. Based on such identification systematic measures should be planned to eliminate them where possible and reduce them when not possible. It is important to plan practices and apply appropriate systems and educate the operatives who are involved in the chain operation.

Based on various evidences in the literature (Taylor, 2006; EPA 2000; Azevedo et al., 2012; Das 2018) it is now established that Lean and Green (LG) practices can be effectively used in any industry to improve their sustainability performances by eliminating wastes and emissions. In addition, there are evidences of innovative applications of LG steps for substantially reducing operation costs and making the organization resilient to most of the natural calamity based disasters. Kraft food's underground warehouse based innovation (AD 2011) not only offers them cost and 
International Journal of Mathematical, Engineering and Management Sciences

Vol. 4, No. 2, 259-275, 2019

https://dx.doi.org/10.33889/IJMEMS.2019.4.2-022

cooling energy saving but it made the warehouse resilient to most of the natural calamities except earthquake. Similar concept was used by Carolina Heritage Vineyard and Winery (CHVW), Yadkin Valley, Elkin, NC in 2005 to build their wine processing plant and storage for aging at an underground building (Carolina Heritage, 2013). In the case of CHVW they have been saving expenses from: cooling of wines in the storage for aging; pumping of water, heating and cooling loads for the underground offices, and for the pumping of grape juices. Such saving was obvious by taking advantage of lower temperature in the underground level store, and gravity flow of juices from the above ground crushing and pressing.

Collection of food items in the collection center is the starting point of a food SC. Effective design and planning of resources, capacities and locations of collection points are crucial requirements for the environmental and economic sustainability as well as social responsibility of a food SC. The reasons for such cruciality of collection points are: a) quality and quantity of collected food items are dependent on the location of the collection points compared to location of growers, climatic conditions, land quality and available infrastructure in terms of roads, transportation, power, water supply; and supply of manpower with required knowledge and skill; b) availability of required resources for effective collection, storage and preservation, and quality assurance are important for assuring suitable quality for human consumption; c) capacity of collection points is the precondition for the quantity of food to be collected to fulfill targeted market need.

Food items grow in farmlands that are usually quite a distance away from big cities. Other than commercial farmland based growers, most of the food items are grown by farmers located at or nearer to diverse farmlands of a state. In such areas investment by big companies are rare. Based on such situations, collection points operated by cooperatives formed by small business entrepreneurs and farmers may be considered viable options. For easy identifications all the counties in a state, or a state may be considered as a grid. This research considers the collection centers as grid based cooperatives in counties of a state.

The grid-based food collection cooperatives need to have warehouses to store food after collection and to store unsold food after their display in local farmers market for the next display, or to transport to food processing center, and/or retail outlets. In some hilly areas cooperatives may plan a warehouse with lower operating expenses for cooling following the example of Craft food's sustainability innovation (AD 2011). Each collection center personnel should be trained in the quality of food items they collect. The cooperatives should also open new display center when they find prospects to extend their market in a region. A major portion of the food items as grown by the cooperative growers are sold in local display centers and in retail outlets. The remaining foods of the cooperatives are transported to regional or, grid based food processing centers. Food items collected by the cooperatives are grown by local farmers, used mostly as inputs to both staple and non-staple processed food, and dairy products. The collected foods also include perishable ones that are packaged by the processing center by including non-harmful preservatives for selling through retail chains. The processing centers are the units of sustainable food supply chain that produces sustainable food and markets through retails chain outlets and through their own outlets. The proposed food SC is a combination of regional SC grids. Each grid consists of set of cooperatives with collection centers, and local farmers markets, retail outlets, and sales outlets operated by the processing centers. Given the current food SC situation, it is apparent that such grid based collection cooperatives have the potential to prevent generation of wastes and emissions in most of the cases at the collection points by providing LG based training to the operatives of cooperatives for improving environmental and economic sustainability. Since the operatives 
International Journal of Mathematical, Engineering and Management Sciences

Vol. 4, No. 2, 259-275, 2019

https://dx.doi.org/10.33889/IJMEMS.2019.4.2-022

involved in the cooperatives are familiar with the growing and collection process such training combined with resources for preservation and storage will eliminate current wastes and prevent future generation. This research is motivated based on the discussed apparent improvement potentials and research based evidences for improving sustainability by applying LG based systems. Establishment of such grid based food SC based on the proposed design model will be able to contribute substantially for improving sustainability of the US food SC. This study will contribute towards reduction of food losses and wastes towards ensuring food for the growing population as recommended by various publications (De Steur et al., 2016).

The paper is organized in the following way: relevant literature is reviewed in the next section, Section 3 presents methodology and the mathematical model for designing Lean, green and resilience based food SC, Section 4 illustrates the design model using a numerical example and Section 5 concludes and discusses.

\section{Study of Literature}

Two streams of research that created background for this research are: Lean, green and resilience based study in food SC; and the studies on food SC sustainability.

\section{Lean, Green and Resilience based Study in Food SC}

Study on Food SC that used LG systems are very limited. There are some distinguishing researches, like Taylor (2006) that took strategic consideration in the development of agi-food SC by applying Lean Tools in the Value Stream Mapping analysis of the SC to identify various wastes, waste reasons, and could improve overall value chain of UK Pork sector based on the author's previous similar study in 2005. Taylor's study applied various Lean tools including integrating supply and demand side of the chain by using PULL system. In fact, this integration used effectively green based supplier buyer partnering and cooperation. The entire value chain was analyzed for flow balancing, quality improvement, and minimization of waste generation (solid, liquid) and improving economic sustainability by considering optimum location for processing centers. Recent literature survey by De Steur et al. (2016) provides more insights on reduction of food wastes through application of Value Stream Mapping. De Steur et al.'s study identified primary production processing, storage and food services center as the main waste generation points in the SC. The review study identified lead time as the most important applicable performance indicator. By this review study the authors provided potential for using Lean based value stream mapping as an effective tool for reducing food wastes in the food SC.

Lean approach based on five fundamentals, lean tools JIT, Poke Yoke, Kaizen, value stream, and seven types of wastes have been used by several studies to make the SCs more competitive in terms of better quality and lower cost (Shah and Ganji, 2017). Shah and Ganji (2017) studied a baked food supplier operation by applying lean approach and could establish effectiveness of such approach. In each of lean based studies overall improvement is mainly achieved by eliminating wastes and stream lining the operations. So, Shah and Ganji's research is relevant to this study.

Reis et al. (2018) proposed a model based approach and formulated a conceptual framework for evaluating integration of lean and green system in the monitoring system of a food SC in the coffee sector. For evaluating LG integration, the authors visited coffee producing properties in Columbia and conducted interview-based survey for finding out the effectiveness of LG based tools used by the properties. Their finding showed that LG integrations had been successfully used in the selected properties and they were effective in reducing food wastes and emissions. 
International Journal of Mathematical, Engineering and Management Sciences

Vol. 4, No. 2, 259-275, 2019

https://dx.doi.org/10.33889/IJMEMS.2019.4.2-022

\section{Studies on food SC Sustainability}

For this stream understanding the waste reasons and the points for waste generation facilitated planning steps to improve sustainability. Considering that a substantial amount of food waste happens in the food production or processing industries and (approximately 39\% in EU) from the farm to fork, Raak et al. (2017) reviewed studies on food losses in the processing stage and natural phenomenon by which food items become waste. Their review study excluded wastes by consumers. Such waste already been established crucial based on finding in FAO (2011) study that $1 / 3 \mathrm{rd}$ of the world-wide food is wasted from the production at the farm to consumption point. It is apparent that due to such waste of food entire amount of energy and water spent in production also been wasted. This waste may only be thought of to add to environmental wastes and creation of emissions and greenhouse gas by spending fuel energy (Papargyropoulou, 2014). So, it is apparent that food SC can be sustainable by eliminating or preventing such waste generation according to goals set in United Nations (2015) to become more sustainable world by 2030. Raak et al. (2017) mentioned two types of food wastes, such as Food item lost in the form of residues, faulty batch, by product, and samples kept for analysis. And the next is food that are discarded or rejected at the retail or house hold levels. Through the literature study the authors discussed on processing techniques and requirements of quality assurance for their study of first waste and; physical, chemical or biological process by which food items become suboptimal to be considered as the second waste.

With the increase of population, growth in food production and consumption have also been occurring to keep pace with the food requirements. Such growth in consumption and production also increased generation of food waste, emissions and greenhouse gas (Li et al., 2014). Review study of agri-food SC chains in Dania et al. (2018) mentioned that collaborations among the various stakeholders of food SC are needed. As mentioned earlier collaboration is a part of green effort which is reestablished in this review study considering several behavioral factors including joint efforts, sharing SC activities, adaptation, trust, commitment, and power of a party, and continuous improvement for meaningful collaboration. Allaoui et al. (2018) proposed a twostep model-based decision-making approach for designing a sustainable food SC. The study attempted partner selection considering number of sustainability indicators in the first step and in the second step they formulated a multi objective mathematical model to optimize the SC design. The research considered water and $\mathrm{CO}_{2}$ footprint including number of job created and economic costs in their multi-objective model. The second step dealt selection of suppliers, locating distributors and transformers (processing stations) to satisfy market demand within minimum cost and environmental impacts.

Based on the study of above research the proposed research model of this paper is developed. In fact, the approaches taken in the above studies created the bases for this paper. The research contributed in planning lean, green and resilience based steps found in the literature for the cooperative collection points which are mostly run by under-privileged, underfunded out of the cities and sub-urban populations. 
International Journal of Mathematical, Engineering and Management Sciences

Vol. 4, No. 2, 259-275, 2019

https://dx.doi.org/10.33889/IJMEMS.2019.4.2-022

\section{Methodology}

For achieving sustainability and resiliency this research integrates various LG based tools and systems in the planning of food SC. Such integration is planned to prevent generation of wastes at the sources and to reduce or eliminate when prevention is not possible. There are multiple sources of waste generation and similar points of already generated wastes in food SC (Beitzen-Heineke, et al., 2017) where LG based tools and systems have been proven to be effective (EPA 2000; Azevedo et al., 2012; Taylor, 2006). Based on literature based evidences LG based tools and systems have potential to address multiple wastes in food SC that are generated at multiple sources. A mathematical model based approach is proposed in this research to effectively integrate such tools and systems for designing a sustainable food SC.

\subsection{Notations}

This section includes Notations used in the formulation of model.

\section{Indices}

ap $\in A P$ : applicability scenario of improvement steps.

$e \in E$ : waste reasons for collected food items by grid network $n$.

$h \in H:$ LG based waste prevention steps that may include training for a) quality assurance, b) to reduce production waste; c) capacity expansion support to growers, d) obtaining funds for growers. $i \in I$ : inputs for the food products, inputs include fruits, vegetables, staple food items ( rice, wheat, rye).

$j \in J$ : sustainable food processing center.

$m \in M$ : market where the SC sends the food item to their own or retail outlets.

$n \in N$ : sustainable food grid.

$p \in P$ : product (food) of different variety, such as fresh produce; processed; bakery; miscellaneous for special diet based food items.

$r \in R$ : denotes lean and green based waste prevention steps applicable at food processing plant.

$s \in S$ : supply sources for input items, in this grid based food collection network, suppliers are in fact growers.

$v \in V$ : index for LG based sustainability and resilience improvement steps such as : partnering with neighboring grid, and others to be followed, steps to reduce and reuse water.

$w \in W$ : warehouses at food collection centers.

$w s \in W S$ : wastes generated/identified in the processing plant.

Parameters and Variables (Parameters are in capital letters)

$c n_{n w i}$ : receiving of inputs $i$ at warehouse $w$ of collection network grid $n$.

$C A P_{n p j}$ : be the processing capacity of plant $j$ of grid $n$ for processing product $p$.

$c a p_{i w}$ : capacity of the warehouse to accommodate collected input $i$ supplied by the supplier.

$C I H_{i h}$ : Cost of preventing waste for input $i$ by applying inhibition step $h$.

$C I M_{i v}$ : cost of obtaining improvement for input $i$ quantity by LG based improvement step $v$.

$C O L C_{i s}$ : cost for collecting input $i$ from supplier $s$.

$C T R_{i w j}$ : cost for transporting per unit input $i$ from warehouse $w$ to plant $j$ or reverse.

$C P L_{p j r}$ : cost of preventing waste generation for production of product $p$ in plant $j$ by LG step $r$.

$F L G_{p r}$ : fixed cost for lean and green step $r$ for preventing waste generation for product $p$.

$F A C_{w a c}$ : fixed cost for allocating a warehouse $w$ to supply applicable points $a c . a c=1$ for collection center, $a c=2$ for allocating to processing plant $j, a c=3$ for allocating to supplier $s$. 
International Journal of Mathematical, Engineering and Management Sciences

Vol. 4, No. 2, 259-275, 2019

https://dx.doi.org/10.33889/IJMEMS.2019.4.2-022

$D X_{m p}$ : be the overall demand for the food product $p$ produced and marketed by the SC at regions or markets $m$.

$F P_{p j}$ : Fixed cost for setting plant $j$ for product $p$.

$F S_{n s}$ : fixed cost for obtaining inputs from supplier $s$ in grid $n$ by creating collaborative relation.

$F I M_{v n}$ : Fixed cost for applying improvement steps $v$ in grid $n$.

$F H_{h n}$ : fixed cost for improved step $h$ in grid $n$.

$h i p_{i h}: 1$, if Lean and green based step $h$ is applied to inhibit waste generation for input $i$.

$H L R_{p j r}$ : the maximum reduction of waste $p$ possible by the preventive step $r$ at plant $j$.

$i m_{\text {nvap }}$ : \% of improvement for collection quantity at collection network grid $n$ by lean and green

(LG) based sustainability and resilience improvement step $v$ at applicable scenario $a p$.

$i n_{n i}$ : input $i$ needed by grid $n$.

$i s_{v n}: 1$, if LG based improvement step $v$ is applied by network $n ; 0$ otherwise.

$i n h_{\text {nieh }}$ : estimated possible wastes of input $i$ that can be inhibited in grid $n$ by LG based steps $h$

through inhibiting error reasons $e$.

$g e_{n i v}$ : estimated gain in inputs $i$ obtained by the application of LG based improvement step $v$.

$g r_{n w}: 1$ if the warehouse $w$ is open in grid $n ; 0$ otherwise.

$L d_{j w}, H d_{j w}$ travelling distances (lower level and higher level) between processing plant $j$ and warehouse $w$.

$L t r_{s w}, H t r_{s w}$ : transportation distance from supplier $s$ to warehouse $w$ (lower and higher level).

$M G_{n i v}$ : maximum possible reduction of wastes for collected inputs $i$ by applying of LG based improvement step $v$.

$M X_{\text {nieh }}$ : maximum possible waste generation inhibition by LG based step $h$ due to waste reason $e$ for input $i$ in grid $n$.

$P R C_{p j}$ : Cost of realizing product $p$ using plant $j$.

$P R W_{n p j w s}$ : possible waste $w s$ as $\%$ of total finished goods at scenario $t$ generated/identified in the processing plant $j$.

$p v n_{\text {nieh }}$ : LG based steps $h \in H$ to inhibit the waste reason $e$ for grid $n$.

$p_{e}$ : probability of deterioration reason $e ; p_{t}$ : probability of scenario $t$.

$r e l_{n s}: 1$, if grid $n$ has developed good relationship with supplier $s$ to be a cooperative collection center; 0 otherwise.

$s e_{n i}$ : shortage/excess of inputs $i$ from collection network of grid $n$ based on demand.

$t w_{n p j}$ : total wastes generated in the plant $j$ in grid $n$ when processing product $p$.

$R W_{n j w s t}$ : denotes the possible waste $w s$ as $\%$ of total finished goods at scenario $t$ generated/ identified in the processing plant $j$.

$U I_{n p i}$ : per unit input requirements for finished product $p$ for the food input items $i$ needed for grid $n$.

$u_{p j}=1$, if product $p$ is assignment to plant $j, 0$ otherwise.

$v h_{s w}: 1$, when warehouse $w$ is open to receive food items from supplier $s ; 0$ otherwise.

$v w_{w j}: 1$, if warehouse $w$ is assigned to supply processing plant $j ; 0$ otherwise.

$w c l_{\text {neit }}$ : percentage of waste for input food items $i$ of collected input in grid $n$ due to the waste reason $e$ in scenario $t$.

$x_{n p j m}$ : product $p$ realized by the processing center $j$ of grid $n$ to fulfill demand in market $m$ through sales outlets $o$. including general retail, fresh food retail, and grid market at period $t$ and $e x_{n p j m}$ is effective amount processed product from the plant.

$Z_{n i s}$ : food input $i$ received by grid $n$ from their supplier or growers $s$.

$w_{r p l} l_{n p r r}$ : reduction of waste for product $p$ by the preventive step $r$ considering all the scenarios at plant $j$ in grid $n$. 
International Journal of Mathematical, Engineering and Management Sciences

Vol. 4, No. 2, 259-275, 2019

https://dx.doi.org/10.33889/IJMEMS.2019.4.2-022

\subsection{Problem Statement and Formulation of Mathematical Model}

This section includes problem statement and formulation of model considering various food SC components. Let $n$ be a sustainable food SC grid of a region which is a combination of multiple cooperatives. The grids are interdependent but unlike current US and EU based food SC controlled by high-powered retailers, cannot break easily because of supply or transportation system failure. Here cooperatives of collection centers, processing centers, distribution centers are bound to work as partnering organizations for their survival. In addition, most of their transactions are local within a very short transportation distance, and inter-grid cooperation is obviously partner like for marketing as well mutual support for common interest.

The grid-based food SC considers $D X_{m p}$ be the overall demand for the product $p$ (food) at various market $m$ of different USA regions. For designing sustainable SC for fulfilling this demand in targeted market $m$ equation (1) computes $x_{n p j m}$ product $p$ to be realized in the processing center $j$ of grid $n$.

$\sum_{j \in J} \sum_{n \in N} x_{n p j m}=D X_{m p} \quad \forall m, p$

Based on this demand and product to be realized and marketed the food SC design considers: a) Design and Management of Collection Network for Inputs; b) Planning Warehouses for Receiving Inputs from Suppliers; c) Planning and Design of Processing Plants.

\section{a) Design and Management of Collection Network for Inputs}

Based on usage of inputs per product this subsection formulates input requirements to fulfill targeted demand. It then estimates possible imbalances comparing input requirements and the average amounts of inputs obtainable from collection networks. For resolving imbalances and thus improving sustainability and resilience it integrates LG based improvement steps.

Overall inputs needed to fulfill market demand that a grid based food SC plans to market may be defined by constraint (2) by considering usage of inputs to produce a product. Constraint (3) plans to open a warehouse for the grid for keeping the inputs

$$
\begin{array}{ll}
\sum_{p \in P} \sum_{j \in J} \sum_{m \in M} x_{n p j m} U I_{n p i}=i n_{n i} & \forall n, i \\
i n_{n i} \leq g r_{n w} B N & \forall n, i, w
\end{array}
$$

Based on the past records cooperative collection center of grid $n$ receives $Z_{n s i}$ input $i$ from supplier if the collection network establishes and maintains reliable business relation with the supplier. Total collected amount of food by a grid in their warehouses may be defined by (4). The cooperative collection network sends their collected inputs to processing plant of the grid from the warehouse. Constraint (5) allocates warehouse $w$ to supply to plant $j$. Constraint (6) ensures allocation of the warehouse to supply a plant only after its opening; Constraint (7) balances inputs needed by the SC with the collected amount by the grid to estimate shortage or excess, if any. 
International Journal of Mathematical, Engineering and Management Sciences

Vol. 4, No. 2, 259-275, 2019

https://dx.doi.org/10.33889/IJMEMS.2019.4.2-022

$$
\begin{array}{ll}
\sum_{w \in W} c n_{n w i}=\sum_{s \in S} \operatorname{rel}_{i s} Z_{n s i} & \forall n, i \\
c n_{n w i} \leq v w_{w j} B N & \forall n, w, j, i \\
v w_{w j} \leq g r_{n w} & \forall n, w, j \\
i n_{n i} \leq\left(c n_{n w i}+s e_{n i}\right) & \forall n, i
\end{array}
$$

If there are shortages, SC grids need to take following LG based steps improvement measures (LGMI) to resolve the shortage related issues and make input process resilient to avoid shortages in future.

LGIM1: Taking supply from collection networks of neighborhood grids $(v=1)$ if they have extra quantity to sell or share through a contract. By such collection, LG based collaboration and flexibility for increasing their capacity to comply with demand change and supply shortage in future will be created, which is an absorptive resilience step.

LGIM2: Supporting supply sources by collection network cooperatives through providing LG based training on Lean concepts, waste types, applying $5 \mathrm{~S}$, reduction of resources use following EPA (2000), and EPA (2007) cases to apply LG based steps $(v=2)$ to improve productivity by reducing their wastes; using technology for preservation of their products, sustainable irrigation or soil preservation system for keeping the soil wet by reducing water loss. LGIM3: The food collection cooperatives should work with bank or some funding agencies to get funds to support and encourage growers to expand their growing capability $(v=3)$. LGIM 4: Encouraging other local entrepreneurs or growers for boosting their income by investing in food production $(v=4)$. Such encouragement may be publicized by organizing local meeting, advertisement in local newspaper, displaying posters/leaflets at public places. LGIM5: Opening training/support centers and providing information on the possible support that some entrepreneurs may need to obtain funding from bank or other funding organizations $(v=5)$. LGIM6: In addition, study should be conducted for covering entire collection network for all possible supply sources $(v=6)$.

Constraint (8) computes the estimated gain through the LG based improvement steps and constraint (9) limits the gain achievable based on the estimated maximum possible gain (please see the definitions of parameters and variables used in the constraints). Based on the gains in (8) and (9) by the LG based improvement it is apparent that $s e_{n i}$ in constraint (7) will be negative by the improvement steps $v=1$ to 6 , meaning extra quantity will be generated.

$$
\begin{array}{ll}
\sum_{a p \in A P} i m_{n v a p} p_{a p} \sum_{w \in W} c n_{n w i}=g e_{n i v} & \forall n, i, v \\
g e_{n i v} \leq i s_{v i} M G_{n i v} & \forall n, i, v
\end{array}
$$

Each of these steps have the potential to improve sustainability (Economic, Environmental and Social) and resilience of Food SC. It is also apparent that by efficient warehouse and irrigation management it will reduce water and energy use in addition to reducing food waste. These steps 
International Journal of Mathematical, Engineering and Management Sciences

Vol. 4, No. 2, 259-275, 2019

https://dx.doi.org/10.33889/IJMEMS.2019.4.2-022

contribute to resilience by including capacity flexibility that support absorption to contain the disruptions to existing capacity by any calamity, internal sabotage and other risks by using standby, extra, or flexible capacity. By network based partnering it creates avenues for adapting and recovery to the supply system failure of a grid due to some localized calamity (flood, cyclone, damage from severe rain or snow fall), localized insect attack; contamination, and fire that could not be absorbed.

\section{b) Planning Warehouses for Receiving Inputs from Supply Sources}

It includes formulation of warehouse location considering transportation distance for warehouseprocessing center and supplier-warehouse combinations. Under this subsection collections points are considered because warehouse is planned to receive inputs from collection centers. Food SC collection points generate several wastes as reported in Literature (e.g. logistical wastes in Raak et al., 2017). As such wastes at collection points are studied to inhibit waste generation by applying LG based steps. Formulations for possible generation of wastes and LG based prevention steps are presented. Based on the notations defined, the requirements for location of warehouses may be defined by constraints (10) and (11)

$$
\begin{array}{ll}
v w_{w j} L d s_{w j} \leq d s_{w j} \leq H d s_{w j} v w_{w j} & \forall w, j \\
v h_{s w} L t r_{s w} \leq d t r_{s w} \leq H t r_{s w} v h_{s w} & \forall s, w
\end{array}
$$

for deciding optimum location for a warehouse the requirement is to minimize ( $\left.d s_{j w c}+d t r_{w c s}\right)$.

According to constraint (12) a supplier supplies inputs $i$ to the warehouse assigned to it when the warehouse is open. Constraint (13) decides capacity of warehouse based on input items supplied by the suppliers. A warehouse $w$ must be open before allocating it to suppliers according to constraint (14).

$$
\begin{array}{ll}
\sum_{i \in I} Z_{n s i} \leq \sum_{w \in W} v h_{s w} B N & \forall s, n \\
\sum_{s \in S} Z_{n s i} \leq \sum_{w \in W} c a p_{n w i} & \forall n, i \\
v h_{s w} \leq g r_{n w} & \forall s, n, w
\end{array}
$$

Wastes in Collection Center

Before progressing further, it may be noted that scope of this research is up to food collections center and food collection network cooperatives. Based on their observations cooperative of collection center grid operatives know that collection center has variety of wastes out of collected inputs. Wastes at collection points are very much visible and understandable but these collection point wastes do not affect food SC in terms of cost, and other metrics of SC. But effects of these waste are significant on overall food waste of the country, economy of growers, and environmental effect. As such these wastes should be inhibited at the point of generation for overall sustainability 
International Journal of Mathematical, Engineering and Management Sciences

Vol. 4, No. 2, 259-275, 2019

https://dx.doi.org/10.33889/IJMEMS.2019.4.2-022

improvement of the food SC. LG based systems have successfully improved sustainability performances of several organizations through inhibiting various waste types at the point of generation similar to wastes observed in Food SC (EPA 2000). Inspired by such example evidences this study applies LG based prevention steps(LGPV) to improve performance of food SC. Various possible reasons of wastes at collection centers and proposed steps for their prevention are described here:

LGPV1: for preventing wastes from overstocking $(e=1)$ at different scenario $s c$ : By collecting food items more than the quantity the cooperatives cannot sell become unsuitable for human consumption after some days which is waste. For preventing such wastes cooperatives of each grid will organize lean concept based training $(h=1)$ for the operatives of collection center on inventory related wastes and the way to prevent the waste based on demand.

LGPV2: Wastes from quality deterioration $(e=2)$ : Such deterioration of food items may happen due to improper storage condition in terms of temperature, protection from rats and other possible insects that may cause contamination. For such wastes cooperative collection center of the grids should plan to include warehouses, cold storage of sufficient capacity for preservation of food items; and providing training to operatives to use the resources $(h=2)$ for preservation, safety, security and monitoring temperature, humidity and quality of the input items. LGPV3: Wastes from failure to collect right quality food $(e=3)$ : Collecting immature or over mature fruits or vegetables, grains for staple processed food; collection with some defect, collection with some pest/insect-based contamination mark; partially damaged input items due to strike of collection machine or, falling on the ground. For preventing such wastes collection center operatives should be trained $(h=3)$ on the quality and features of food items for collecting, storing, and transportation to prevent this waste type. LGPV4: Waste from transportation to collection points or warehouses by the growers, Waste of spillage during transporting from grower's place to collection point $(e=4)$. Such waste also comes from using improper packaging by the growers for their delivery to the collection centers as well as using improper collection bins at the harvesting points that create wastes affecting overall collection quantity, costs from wastes, and contributing to pollution generation. For preventing such wastes collection center for each grid-based cooperatives should plan to support food suppliers with appropriate type of metallic bins for their collection and transportation to collection points $(h=4)$ to prevent such wastes. By these LG based steps the model includes the philosophy of preventing waste generation (UNEP 2010) in place of end of pipe elimination and reduction based on the study of current practices as available in the literature and USDA, Food department, and WFP, UNEP study documents.

Constraint (15) estimates wastes generated from the waste reasons $e$ described above. Constraint (16) estimates the wastes that may be inhibited by LG based step $h$. Constraint (17) limits inhibition of wastes by LG based steps.

$$
\begin{array}{ll}
\sum_{w \in W} c n_{\text {nwi }} \sum_{t \in t} W C L_{\text {neit }} p s_{t}=\text { wes }_{\text {nei }} & \forall n, e, i \\
\sum_{w \in W} c n_{\text {niw }} \sum_{t \in T} p v n_{\text {nhet }} p_{t}=i n h_{\text {nieh }} & \forall n, i, h, e \\
i n h_{\text {nieh }} \leq h i_{i h} M X_{\text {nih }} & \forall n, i, h, e
\end{array}
$$


International Journal of Mathematical, Engineering and Management Sciences

Vol. 4, No. 2, 259-275, 2019

https://dx.doi.org/10.33889/IJMEMS.2019.4.2-022

Effective collection quantity by a grid is estimated by constraint (18) based on effects of wastes and prevention.

$$
e F C_{n w i}=c n_{n w i}-\sum_{e \in E}\left(w_{e s}-\sum_{h \in H} i n h_{n i e h}\right) \quad \forall n, w, i
$$

\section{c) Planning and Design of Processing Plants}

Constraint (19) limits realization of product from the processing plant

$$
\sum_{m \in M} x_{n p j m} \leq u_{p j} C A P_{n p j} \quad \forall p, j, n
$$

Constraint (20) estimates total wastes as a $\%$ of total realized amount of product generated in the processing plant $j$ by considering the scenario $t$ and waste types (Refer to notations for model parameters and variables).

$t w_{n p j}=\sum_{t \in T} \sum_{w s \in W S} R W_{n p j w s t} p_{t} \quad \forall p, j, n$

Constraint (21) estimates the reduction of waste by a LG based step by considering total scenario for each product-plant combination; constraint (22) limits the maximum achievable waste reduction by a lean and green based preventive step. Here $l_{r p}$ is a $0 / 1$ decision variable to decide application of LG based preventive steps. Considering the waste reduction steps in processing plants and wastes generated, effective realized product may be defined in (23) based on constraints (20 to 22)

$$
\begin{array}{ll}
\sum_{t \in T} P L_{n r t} p_{t} x_{n p j m}=w r p l_{n p j r} & \forall n, p, j, m, r \\
w r p l_{n p j r} \leq l g_{r p} H L R_{p j r} & \forall n, p, j, m, r \\
e x_{n p j m}=x_{n p j m}\left(1-t w_{n p j}\right)+\sum_{r \in R} w r p l_{n p j r} & \forall n, p, j, m
\end{array}
$$

\subsection{Objective Function}

The Objective 1 of the of the cooperative grid based food SC is to maximize product realized by the network processing plants to comply with marketing needs. Since such realization of product by the plants are subject to obtaining optimum inputs by reducing wastes and preventing waste generation in the collection networks and processing plants, maximizing product realization is considered as Objective 1. In fact, this realized amount of product is the net effect of environmental and social sustainability of the SC by minimizing the wastes and facilitating improvement of performance of the supply sources, collection networks and by supporting with resources and by providing required training to improve sustainability, and Objective 2 is to maximize Profit which is the economic sustainability. Objective 1 is to the maximize this cumulative measure: CUM_ENV_SOCIAL SUS (CES)and Objective 2: is to maximize Profit which is the economic sustainability: ECO_SUS; 
International Journal of Mathematical, Engineering and Management Sciences

Vol. 4, No. 2, 259-275, 2019

https://dx.doi.org/10.33889/IJMEMS.2019.4.2-022

Objective 1: maximize : $C E S=\sum_{n \in N} \sum_{p \in P} \sum_{j \in J} \sum_{m \in M} e_{n p j m}$

Objective 2: Maximize Profit= Revenue (REV)-Total Cost (TC)

$R E V=\sum_{p \in P} \sum_{m \in M} V C_{p m} \sum_{n \in N} \sum_{t \in T} \sum_{j \in J} e x_{n p j m}$

$T C=$ product realization cost $(P R C)+$ Input $\operatorname{cost}(I N C)+$ Transportation cost from Collection center to Processing center and processing center to market $(T R P L)+$ Waste prevention cost $(W P R E)+$ Cost for improving sustainability $(C I S)+$ Collection center operation $\operatorname{cost}(\mathrm{CCOP})+$ fixed cost for establishing collection location $(F C L)+$ cost for electric power and natural Gas, water, city charge for dumping yard and water treatment $(N P L U)$

Details of equations for PRC, INC, TRPL, WRPL CIS, CCOP, FCL, and NPLU are not presented considering these may not be interesting.

\section{Numerical Example}

For illustrating applicability of the model this research considered 5 counties of $\mathrm{NC}$ each with population 50,000 to 100,000 (Craven, Lenoir, Duplin, Nash, Wilson). These counties are moderately developed at the areas where farm foods (fruits, staples, vegetables, chicken/beef/pork meats are grown or produced. 4 products (food) are considered. They include Fresh produce, processed, and special (like specially processed, Beverage, Diets). Each county is considered as a grid. For each grid 2 collection cooperatives with 2 warehouses, and 2 processing plants are considered. Processing plants take collected input items from the warehouses for processing and sending the items to 5 markets considered by each grid. The markets may be retail outlets in NC or outside NC.

For this research main emphasis areas considered are: effective quantity of food items that may be marketed and reduction or prevention of waste generation. Very limited input data are presented. Table 1 presents demand for products 1 and 2 in various markets and Table 2 shows typical inputs supplied by the suppliers. For an example, 13,694 units of inputs are supplied by supplier 1 for grid 1.

Table 3 presents model output on the inputs needed by typical grid to fulfill market demand for product. The Model computes the inputs requirements $\left(i n_{n i}\right)$ using constraint (2) based on usage of inputs and demand for product.

Table 1. Typical demand of 2 products out of total 4 at various markets

\begin{tabular}{|c|c|c|c|c|c|c|}
\hline & \multicolumn{5}{|c|}{ Demand of product in the markets } & \multirow{2}{*}{ Total } \\
\hline Product & $\mathbf{1}$ & $\mathbf{2}$ & $\mathbf{3}$ & $\mathbf{4}$ & $\mathbf{5}$ & 311,822 \\
\hline 1 & 61,570 & 61,806 & 60,032 & 62,362 & 66,052 & 424,076 \\
\hline 2 & 101,152 & 78,364 & 90,908 & 81,154 & 72,498 & \\
\hline
\end{tabular}


International Journal of Mathematical, Engineering and Management Sciences

Vol. 4, No. 2, 259-275, 2019

https://dx.doi.org/10.33889/IJMEMS.2019.4.2-022

Table 2. Typical average amount of inputs supplied by 6 suppliers in grid 1

\begin{tabular}{|c|c|c|c|c|c|c|c|}
\hline & \multicolumn{7}{|c|}{ Average inputs supplied by the suppliers in a typical grid } \\
\hline Inputs & $\mathbf{1}$ & $\mathbf{2}$ & $\mathbf{3}$ & $\mathbf{4}$ & $\mathbf{5}$ & $\mathbf{6}$ & Total \\
\hline 1 & 13,694 & 14,898 & 13,234 & 8,990 & 12,833 & 11,123 & 74,772 \\
\hline 2 & 13,582 & 14,509 & 9,035 & 10,710 & 13,696 & 11,004 & 72,536 \\
\hline
\end{tabular}

Table 3. Model output on requirements of inputs by each grid to fulfill market demand

\begin{tabular}{|c|c|c|c|c|c|c|}
\hline & \multicolumn{5}{|c|}{ Amount of inputs needed } & \\
\hline Grid & $\mathbf{1}$ & $\mathbf{2}$ & $\mathbf{3}$ & $\mathbf{4}$ & $\mathbf{5}$ & Total \\
\hline 1 & 89,542 & 29,889 & 118,925 & 89,763 & 163,007 & 491,126 \\
\hline 2 & 84,678 & 24,367 & 36,733 & 93,921 & 170,300 & 409,999 \\
\hline
\end{tabular}

Table 4. Model estimate for the amount of inputs collected by the typical grids

\begin{tabular}{|c|c|c|c|c|c|c|}
\hline \multicolumn{7}{|c|}{ Collected inputs } \\
\hline Grid & $\mathbf{1}$ & $\mathbf{2}$ & $\mathbf{3}$ & $\mathbf{4}$ & $\mathbf{5}$ & Total \\
\hline 1 & 74,772 & 72,536 & 64,497 & 63,662 & 70,255 & 345,737 \\
\hline 2 & 57,795 & 62,960 & 52,995 & 67,140 & 56,922 & 643,534 \\
\hline \multicolumn{7}{|c|}{ Short(-) /excess of inputs in Grids } \\
\hline 1 & $-14,770$ & 42,647 & $-54,428$ & $-26,101$ & $-92,752$ & \\
\hline 2 & $-26,883$ & 38,593 & 16,262 & $-26,781$ & $-113,378$ & \\
\hline
\end{tabular}

For an example, the model estimated 89,542 units of input 1 is needed by grid 1 to fulfill market demand through its supply from the plants. Table 4 presents collected inputs by typical grids from the suppliers with whom the grid could establish reliable partnering relationship to supply to grid's warehouses. The model estimated collected inputs through constraint (4). For an example grid 1 collected 74,772 units of input 1 . Table 4 also shows short and excess as computed by model constraint (7) for grids 1 and 2. These short excesses may be verified by comparing data in Table 3 and 4.

The model estimated possible wastes by constraint (15) considering various possible scenarios for waste reasons. Model constraints (16) and (17) estimated improvements considering waste reasons, possible scenarios for applying LG based steps LGPV1 to LGPV4 and maximum possible improvements achievable. The model estimated overall status of inputs in constraints (18). Table 5 presents the overall status of the inputs including the excesses and shortages for typical grids after considering LG based inhibition steps and wastes generated due to various reasons. As is apparent LG steps improved the situation but more improvement needed for expected sustainability status. 
International Journal of Mathematical, Engineering and Management Sciences

Vol. 4, No. 2, 259-275, 2019

https://dx.doi.org/10.33889/IJMEMS.2019.4.2-022

Table 5. Overall status for the collected inputs compared to units needed to fulfill demand for typical grids

\begin{tabular}{|c|c|c|c|c|c|c|}
\hline \multirow[b]{2}{*}{ Grids } & \multicolumn{5}{|c|}{ Collected inputs and short/excesses compared to demand } & \multirow[b]{2}{*}{ Remarks } \\
\hline & 1 & 2 & 3 & 4 & 5 & \\
\hline 1 & 89,633 & 87,460 & 79,396 & 75,869 & 83,674 & Overall collected inputs \\
\hline short /excess & 91 & 57,571 & $-39,529$ & $-13,894$ & $-79,333$ & Compared to demand \\
\hline 2 & 68,559 & 75,127 & 64,574 & 79,175 & 67,083 & Overall collected inputs \\
\hline short/excess & $-16,119$ & 50,760 & 27,841 & $-14,746$ & $-103,217$ & Compared to demand \\
\hline
\end{tabular}

Table 6. Wastes generated in plants of typical grids that may be prevented by LG steps

\begin{tabular}{|l|l|l|l|l|l|l|l|l|l|l|l|l|}
\hline Grids & 1 & 1 & 1 & 1 & 2 & 3 & 3 & 3 & 4 & 4 & 4 & 4 \\
\hline Products & 1 & 2 & 3 & 4 & 4 & 2 & 2 & 3 & 1 & 1 & 4 & 4 \\
\hline Plants & 1 & 1 & 1 & 1 & 1 & 1 & 2 & 2 & 1 & 2 & 1 & 2 \\
\hline $\begin{array}{l}\text { Generated } \\
\text { Wastes (units) }\end{array}$ & 838 & 5,932 & 7,053 & 5,688 & 5,869 & 6,968 & 7,116 & 3,541 & 6,743 & 6,589 & 986 & 7,691 \\
\hline $\begin{array}{l}\text { Prevented by } \\
\text { LG steps } \\
\text { units) }\end{array}$ & 859 & 6,126 & 7,500 & 6,137 & 6,196 & 7,464 & 7,348 & 3,738 & 7,119 & 6,804 & 1,041 & 8,179 \\
\hline
\end{tabular}

Table 7. Variation of Profit with the variation of $C E S$

\begin{tabular}{|c|c|c|c|c|}
\hline CES (Units) & Profit (\$) & Revenue (\$) & Total Cost (\$) & Model Definition \\
\hline $1,251,594$ & $5,929,077$ & $10,784,100$ & $4,855,023$ & Max CES \\
\hline $1,251,594$ & $6,098,167$ & $10,915,220$ & $4,817,056$ & Max Profit, S.t. CES $\geq 1,251,594$ \\
\hline $1,251,553$ & $6,103,095$ & $10,914,830$ & $4,811,736$ & Max Profit, S.T. CES $\geq 1,251,553$ \\
\hline $1,251,403$ & $6,110,059$ & $10,913,260$ & $4,803,205$ & Max Profit, S.T. CES $\geq 1,251,403$ \\
\hline $1,251,253$ & $6,114,667$ & $10,911,660$ & $4,796,991$ & Max Profit, S.T. CES $\geq 1,251,253$ \\
\hline $1,251,103$ & $6,119,422$ & $10,910,110$ & $4,790,683$ & Max Profit, S.T. CES $\geq 1,251,103$ \\
\hline $1,250,953$ & $6,122,922$ & $10,908,510$ & $4,785,591$ & Max Profit, S.T. CES $\geq 1,250,953$ \\
\hline $1,250,803$ & $6,125,119$ & $10,907,110$ & $4,781,990$ & Max Profit \\
\hline
\end{tabular}

In addition to wastes and inhibition steps in collection centers, the research considered generation of food wastes and LG based preventive steps for such generation under Estimation of Food Wastes in the Processing Centers. Table 6 presents the estimated food wastes based on possible waste generation reasons at various scenarios. Table 6 also shows wastes that may be prevented by applying lean and green based steps discussed above. It is apparent that entire amount of processing wastes may be prevented by applying appropriate LG steps

Table 7 presents Pareto optima solutions for Profit VS Equivalent Environmental and Social Sustainability measure $(C E S)$ which is also demonstrated in Figure1. It apparent that with the improvement of CES profit decreases. Such trend is obvious because of required investment to reduce and prevent wastes for improving CES. These Pareto Optima solutions provide Food SC Management what-if options to select their expected solution combination. 
International Journal of Mathematical, Engineering and Management Sciences

Vol. 4, No. 2, 259-275, 2019

https://dx.doi.org/10.33889/IJMEMS.2019.4.2-022

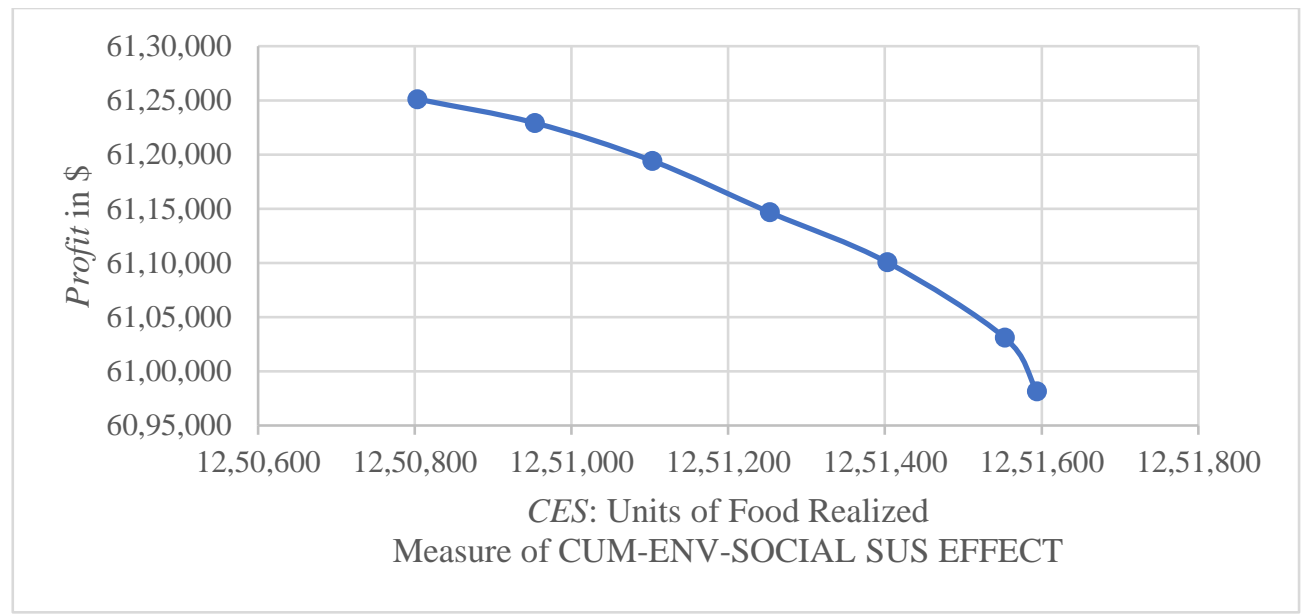

Figure 1. Pareto frontier Profit vs CES (equivalent CUM-ENV-SOCIAL SUS-Measure)

\section{Conclusion}

The overall research approach and the model introduced a new and robust sustainable food SC design and planning approach by involving grid operatives in the management of the cooperatives for collection, distribution and overall sustainability development process. It is apparent that LG system based training and improvement steps are quite adaptable to county or locality based cooperatives when such LG based steps are rooted in mutual trust, cooperation, collaboration and supporting inter-organizational process for eliminating wastes for improving stake holder value (Womack and Jones, 2003). Since grid operatives are conversant on the wastes and waste reasons for food growing process, collection, and distribution process, the proposed LG based sustainability improvement steps have the high potential to be successful. The model-based design for selecting location for warehouses, most suitable plants, grids, in addition to applicable lean tools for collection, distribution, and processing of the food items optimized the overall process through waste removal and prevention to improve economic, and environmental sustainability performances. It will also improve the social responsibility and resiliency by making the operatives expert in running the grid based operations effectively through their earned knowledge from training and participating in the grid operations. By including Pareto optima solutions, the research created scopes for USDA and funding agency to study what-if process for supporting such cooperatives development process and encourage local entrepreneurs to invest in grid based SC development process.

\section{Conflict of Interest}

The author confirms that there no conflict of interest to declare for this publication.

\section{Acknowledgements}

This research was supported by EPA Region 4 (Southeast) as a part of a research project titled, "Greening Food and Beverage Industries in North Carolina”. The author gratefully acknowledges the support. 
International Journal of Mathematical, Engineering and Management Sciences

Vol. 4, No. 2, 259-275, 2019

https://dx.doi.org/10.33889/IJMEMS.2019.4.2-022

\section{References}

Allaoui, H., Guo, Y., Choudhary, A., \& Bloemhof, J. (2018). Sustainable agro-food supply chain design using two-stage hybrid multi-objective decision-making approach. Computers \& Operations Research, 89, 369-384.

Azevedo, S. G., Carvalho, H., Duarte, S., \& Cruz-Machado, V. (2012). Influence of green and lean upstream supply chain management practices on business sustainability. IEEE Transactions on Engineering Management, 59(4), 753-765.

Beitzen-Heineke, E. F., Balta-Ozkan, N., \& Reefke, H. (2017). The prospects of zero-packaging grocery stores to improve the social and environmental impacts of the food supply chain. Journal of Cleaner Production, 140, 1528-1541

Dania, W.A.P., Xing, K., \& Amer, Y. (2018) Collaboration behavioral factors for sustainable agri-food supply chain: a systematic review. Journal of Cleaner Production, 186, 851-864.

Das, K. (2018). Integrating lean systems in the design of a sustainable supply chain model. International Journal of Production Economics, 198, 177-190.

De Steur, H., Wesana, J., Dora, M. K., Pearce, D., \& Gellynck, X. (2016). Applying value stream mapping to reduce food losses and wastes in supply chains: a systematic review. Waste Management, 58, 359368

Li, D., Wang, X., Chan, H. K., Manzini, R. (2014). Sustainable food supply chain management. International Journal of Production Economics, 152, 1-8.

Papargyropoulou, E., Lozano, R., Steinberger, J. K., Wright, N., \& bin Ujang, Z. (2014). The food waste hierarchy as a framework for the management of food surplus and food waste. Journal of Cleaner Production, 76, 106-115.

Raak, N., Symmank, C., Zahn, S., Aschemann-Witzel, J., \& Rohm, H. (2017). Processing-and productrelated causes for food waste and implications for the food supply chain. Waste Management, 61, 461472.

Reis, L. V., Kipper, L. M., Velásquez, F. D. G., Hofmann, N., Frozza, R., Ocampo, S. A., \& Hernandez, C. A. T. (2018). A model for Lean and Green integration and monitoring for the coffee sector. Computers and Electronics in Agriculture, 150, 62-73.

Shah, S. R., \& Naghi Ganji, E. (2017). Lean production and supply chain innovation in baked foods supplier to improve performance. British Food Journal, 119(11), 2421-2447.

Taylor, D. H. (2006). Strategic considerations in the development of lean agri-food supply chains: a case study of the UK pork sector. Supply Chain Management: An International Journal, 11(3), 271-280.

Womack, P. J., \& Jones, D. T. (2003). Lean thinking, banish waste and create wealth in your corporation. Free Press, New York.

\section{Links and Websites}

Associated Press-GfK poll conducted in December2014, most Americans favor labeling calories on menus in fast food and sit-down restaurants, https:/www.pbs.org/newshour/health/majority-americanssupport-menu-labeling-restaurants, Accessed 2018, February; from Greenville, NC

AD, Area Development: Kraft's Sustainability based innovation for warehousing http://www.areadevelopment.com/siteSelection/2-28-2011/kraft-foods-springfield-undergroundmissouri022811.shtml, accessed on 2/25/2018, 2011. 
International Journal of Mathematical, Engineering and Management Sciences

Vol. 4, No. 2, 259-275, 2019

https://dx.doi.org/10.33889/IJMEMS.2019.4.2-022

Carolina Heritage, Organic Wine production in NC -our experience, Leaflet of the company published in 2013. Detailed ideas in www.carolinaheritagevinyards.com, accessed om 2/25/2018, 2013.

EPA, Lean and Green Supply Chain: a practical guide for materials and supply chain managers to reduce cost and improve environmental performances, Retrieved on 10/09/16 https://www.epa.gov/p2/leanand-green-supply-chain-practical-guide-materials-managers-and-supply-chain-managers-reduce,2000.

FAO, Global Food Losses and Food Waste - Extent, Causes and Prevention, International Congress SAVE FOOD! at Interpack 2011, Düsseldorf, Germany. www.fao.org/docrep/014/mb060e/mb060e.pdf Accessed 5/2/2018 Greenville, NC, 2011.

UNEP: Waste and Climate Change, http://www.unep.or.jp/ietc/Publications/spc/Waste\&ClimateChange/Waste\&ClimateChange.pdf, accessed and retrieved on 3/5/2018, 2010.

UNEP, International Resource Panel, Priority products and materials: assessing the environmental impacts of consumption and production. United Nations Environment Programme, 2010.

United Nations, Transforming Our World: The 2030 Agenda for Sustainable Development. NY, USA, New York, https://sustainabledevelopment.un.org/post2015/transformingourworld, accessed 5/2/2018 Greenville, NC, 2015. 